\title{
Diagnostic and Therapeutic Advances in Epileptic Encephalopathy with Continuous Spike-Wave of Sleep
}

\author{
Groppa $\mathrm{St}^{1,2,3^{*}}$, Ciolac $\mathrm{D}^{1,2,3}$ and Chiosa $\mathrm{V}^{1,2,3}$ \\ ${ }^{1}$ Department of Neurology, State Medical and Pharmaceutical University, Moldova \\ ${ }^{2}$ Laboratory of Neurobiology and Medical Genetics, State Medical and Pharmaceutical University, Moldova \\ ${ }^{3}$ Centre of Epileptology, Institute of Emergency Medicine, Moldova
}

Submission: March 15, 2017; Published: May 26, 2017

*Corresponding author: Groppa Stanislav, State Medical and Pharmaceutical University, Chisinau, Republic of Moldova, Tel: 373-69145820; Email: st.groppa@gmail.com

\begin{abstract}
The epileptic encephalopathy with continuous spike-waves during sleep (CSWS) is an electroclinical syndrome which affects children mostly between the age of 4 and 7 years old and remains a great challenge for clinicians. The neurocognitive decline plays a negative role in child development and often is the first diagnosed sign in this syndrome (the characteristic electrophysiological features are recorded only during sleep). Herein we present a brief overview of the recent advances in diagnostic and therapeutic issues of the epileptic encephalopathy with CSWS. The original studies presented in the PubMed and NCBI databases were inquired/consulted, research length was 45 years.
\end{abstract}

Keywords: Epilepsy; Continuous spike-wave during sleep; Electrical status epilepticus; Spike-wave index 3.

Abbreviations: ILAE: International League Against Epilepsy; CSWS: Continuous Spike-Wave of Sleep; ESES: Electrical Status Epilepticus; SW: Spike-Wave; SWI: Spike-Wave Index; AED: Antiepileptic Drug; REM: Rapid Eyes Movement; ACTH: Adrenocorticotropic Hormone; tDCS: Transcranial Direct Current Stimulation; IQ: Intelligence Quotient; DQ: Developmental Quotient; EEG: Electroencephalogram; LKS: LandauKleffner Syndrome

\section{Introduction Definition and Concepts}

International League Against Epilepsy (ILAE) defines Epileptic encephalopathy with continuous spike-waves during sleep (CSWS) is an electroclinical syndrome [1] characterized by epileptic seizures, neurocognitive regression and electrophysiological changes on electroencephalogram (EEG), namely electrical status epilepticus of sleep (ESES). However, later revised ILAE terminology from 2011-2013 didn't modify this concept [2]. In 1971 Tassinary et al. [3] was the first to describe and propose the notion of ESES as a "subclinical" state with electrographic changes occurring in at least $85 \%$ of nonREM sleep.

Subsequently, the Commission on Classification and Terminology of ILAE introduced the definition of CSWS [4], which is still under debate in scientific literature as well as by ILAE, because, e.g. "the use of CSWS and ESES is a cause of major diagnostic confusion and should be abandoned in its current form". In this context, the ILAE Committee instead of two terms should propose one term, e.g. CSWS-related encephalopathy or at least change the acronym from CSWS to ECSWS (E meaning epileptic encephalopathy), in order to avoid the diagnosis of an electroclinical syndrome based on EEG findings (as the term CSWS implies) [5]. However, many publications still make no difference between ESES and CSWS [6]. Tassinari et al. [7] proposed to call it "The Penelope syndrome" "as in the myth of Penelope, the wife of Odysseus, what is weaved during the day will be unraveled during the night". Any way, it is necessary to develop common terminology and conceptualization of CSWS/ ESES [8].

\section{Clinical Manifestations}

CSWS represents about $0,5-0,6 \%$ of childhood epilepsies, affecting children between the age of 4 and 7 years, rarely between 10-12 years. Male to female ratio is 60/40 [9]. The core clinical manifestations of CSWS are epileptic seizures and neurocognitive regression. Approximately $80 \%$ of patients present one seizure type [10], with the most common seizures types including clonic or tonic-clonic, typical or atypical absence seizures. Focal simple and focal complex seizures as well may be observed [11]. 
Neurocognitive regression emerges within 2-3 years after the seizure onset [12]. Depending on the etiology and comorbidities, the neurocognitive decline affects the quality of life in $50 \%$ of cases [13]. Improvement of skills follows the reduction of ESES and seizures during puberty [11].

\section{Diagnostic Work-up Neuroimaging}

Brain structural abnormalities on neuroimaging can be found in $30-59 \%$ of patients with CSWS $[14,15]$. Perinatal vascular lesions, malformations of cortical development and delayed myelination being the most frequent lesions associated with CSWS $[16,17]$. Recently the functional thalamic abnormalities were described in patients with CSWS [18]. Other rare diseases accompanied by CSWS are hereditary dentatorubral-pallidoluysian atrophy [19] and familial hereditary encephalopathies [20]. Benign Epilepsy of Childhood with Centro temporal Spikes, Benign Epilepsy of Childhood, Acquired Epileptic Aphasia (LKS) and Lennox-Gastaut syndrome are also associated with CSWS [11].

\section{Electroencephalography}

In the last 2009 ILAE Guidelines on Electroencephalography in CSWS [21] a scale of spike-wave index (SWI) was described in order to facilitate the comparison among different available scientific data: 0 (no spike-wave [SW]); 1 (0-20\% SW); 2 (20$50 \%$ SW); 3 (50-85\% SW); 4 (>85\% SW). In this way of thinking, the most appropriate criterion for CSWS/ESES syndrome seems to be the presence of at least $50 \%$ of epileptiform activity during non-REM and/or REM sleep [21]; this is different from previous studies reporting epileptiform epochs of at least $85 \%$ of recorded non-REM sleep [3,22]. Firstly, SWI was described by the most of authors as the percentage of non-REM sleep occupied by SW $[22,23]$, typically in the 1.5 to $3 \mathrm{~Hz}$ range [11]. Since 2005, SWI has been defined as the percentage of 1-second epoch with at least one SW relative to the total 1-second epoch in non-REM sleep [14,24].

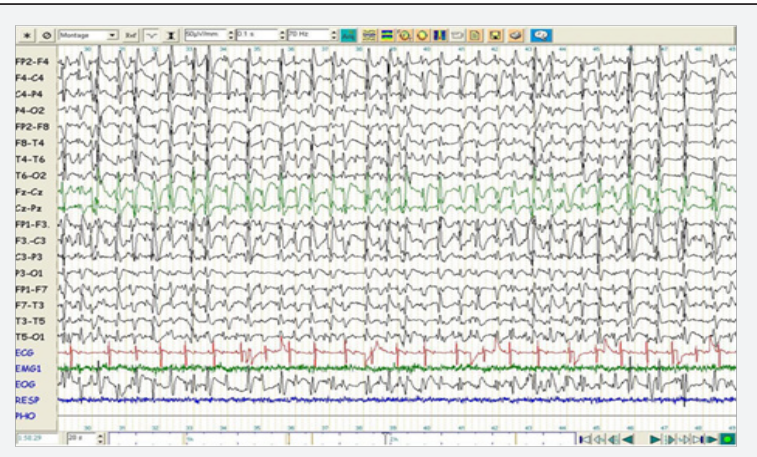

Figure 1: Sleep EEG pattern of 4 years 6-month-old patient with CSWS, male, video-EEG night monitoring.

Standing on SWI, typical and atypical ESES were distinguished [25]. In typical ESES, SWI is 85-100\%, whereas in atypical ESES it reaches 50-85\% [25]. According to the ILAE Guidelines and basing on the distribution of SWs, ESES/CSWS was classified into focal, multifocal, unilateral, asymmetric, and symmetric bilateral and diffuse [21]. Recently, depending on the maximum amplitude of SW on EEG, anterior (if the maximum amplitude is recorded in frontal, frontocentral or frontotemporal areas) and posterior (posterior temporal, temporo-occipital or occipital areas) ESES patterns were proposed [25] (Figure 1).

It is worth of mentioning the fact that SW may occur at the place where the highest and most synchronized slow waves correspond to brain tissue with an increased susceptibility to synchronization [26]. The hierarchical network organization with leading role of precuneus and thalamus appears to be specific for CSWS as it is resolved after successful treatment [27]. The continuous spike-wave pattern disrupts the typical sleep, the EEG background and stages of non-REM sleep cannot be differentiated [28].

\section{Treatment}

Despite many modern advances, epileptic encephalopathy with CSWS still remains a condition difficult to treat. Treatment strategies are widely discussed in the scientific community, including pharmacological and non-pharmacological options. Concerning the pharmacological treatment, an "aggressive" therapeutic approach should be taken into consideration, due to the fact that the goal of the treatment "is not only to control clinical seizures but also to improve neuropsychological functions and prevent potential cognitive deterioration" [29]. There is no consensus regarding the treatment of seizures and effectiveness of antiepileptic drugs (AEDs) [28], but benzodiazepines (particularly clobazam) and valproate [22,30], levetiracetam and steroids [30] can be considered as AEDs of choice. In another study, AEDs of the first choice recommended were levetiracetam and clobazam [31].

It has been shown that levetiracetam is more effective in children with CSWS caused by a brain structural lesion (symptomatic group) [32] and in non-refractory patients compared to the group of refractory patients [24]. Given the severity of syndrome, the control on seizures can be reached by considering polytherapy [11]. Ethosuximide and sulthiame are effective drugs in CSWS and can be tried as monotherapy or in combination [33]. Lacosamide in add-on therapy is safe and $75 \%$ of patients become responders [34]. Efficiency of topiramate in CSWS, especially in refractory cases, was demonstrated in a retrospective study, which showed a decrease of EEG abnormalities, and amelioration in clinical and cognitive performance [35].

Acetazolamide turned to be effective and should be considered as adjunctive medication in CSWS treatment [36]. Nowadays, administration of corticosteroids in CSWS treatment is an important issue: on one hand, corticosteroids showed a proved effectiveness and have long lasting beneficial effects in refractory cases $[30,37,38]$, particularly methylprednisolone with a $83 \%$ effective rate [39], dexamethasone as an effective 
and tolerable therapy [40], prednisolone [38] or hydrocortisone can be used [37].

On the other hand, use of corticosteroids is limited by their significant side effects, obliging an administration for a short period of 1-2 months with subsequent dose tapering for following 1-3 months [30]; though, some authors suggest treatment duration almost for 21 months [37]. It is necessary to mention that no serious or life-threatening side effects were reported in the largest study regarding the treatment with corticosteroids [37]. Little evidence regarding the use of immunoglobulin's in CSWS treatment exists and moreover, their use is limited by the risk of complications and high costs [30].

Therapeutic effects of adrenocorticotropic hormone (ACTH) in CSWS are self-limited as observed in some early studies [41,42]; however, from this drug could benefit non-responder patients in short treatment cycles [43]. Efficiency of ketogenic diet still remains unclear; a study on 5 non-responder patients to conventional AEDs reported lack of response in 3 patients after 24 months of ketogenic diet [44]. Regarding the efficacy of AEDs, we should keep in mind that despite reducing the seizure frequency some of them can worsen ESES/CSWS.

Carbamazepine, phenytoin and phenobarbital negatively impacts EEG and neuropsychological outcome [45,46]. Epilepsy surgery as an early therapeutic modality should be considered for selected patients with symptomatic ESES/CSWS [29]. The type of neurosurgical procedure relies on structural etiology: lesionectomy is applied clearly delimited structural abnormalities, e.g. in perinatal infarction [47] or in focal cortical dysplasia [29]. Multiple subpial transections, disconnecting only local cortico-cortical pathways for the disruption of local epileptic circuitries, abolish ESES in Landau-Kleffner syndrome, but unfortunately, only for a short period of time [24].

Instant control of seizures, amelioration of EEG abnormal patterns and neurocognitive decline can be achieved by functional hemispherectomy [16,47-49]. Among the non-pharmacological options, vagal nerve stimulation and transcranial direct current stimulation (tDCS) can be tried. Stimulation of vagal nerve showed modest efficacy $[50,51]$ but still may be taken into account for the treatment of CSWS [52]. TDCS with $1 \mathrm{~mA}$ is well tolerated and reduces epileptiform activity in CSWS [53]. Eventually, in cases refractory to all other traditional treatment approaches, pentobarbital coma titrated to burst-suppression EEG pattern improves EEG anomalies associated with ESES [28]. The success of the treatment depends on the time frame of the therapeutic intervention. The shorter is the ESES period; the lower is residual deficit [31].

\section{Outcome}

Long-term outcome of ESES/CSWS depends on the etiology, duration and response to applied treatment [54]. In AEDtreatment responding patients, idiopathic cases returned to normality and structural cases returned to baseline cognitive skills [33]. Recovery of cognitive performance after discontinuation of CSWS depends on severity and duration of the initial decline [55]; neurocognitive performance tends to improve slowly, for a longer period of time and often remains [6]. So, there is a correlation between the duration of ESES and the residual intellectual deficit [31]; moreover, duration more than 2 years is associated with poor cognitive outcome [56].

Several distinctive studies proposed to classify the outcome into clinical, neurophysiological and neuropsychological [11,32]. These studies confirmed the aforementioned points, especially those dealing with the duration of CSWS, which was the main predictor of severity of the neuropsychological outcome. Low intelligence quotient (IQ) came to be the most useful predictive factor of poor treatment response with corticosteroids in patients with CSWS [37]. Positive response to steroids was significantly associated with a higher IQ/DQ. Shorter duration of CSWS, but not age, etiology or previous AED trials was associated with positive response to steroids [37].

\section{Conclusion}

Epileptic encephalopathy with CSWS is an age-related devastating syndrome characterized by seizures, continuous epileptic discharges during sleep and neurocognitive regression. There is no unanimous view on the choice of the most efficient drug therapy but the treatment should be started as soon as possible and the pharmacological approach should be aggressive. Primary goals of the treatment are: cessation of seizures, normalization of EEG pattern and prevention of neurocognitive decline. Despite the inconstant efficacy of AEDs, corticosteroids are efficient and safe for the treatment of epileptic encephalopathy with CSWS and should be considered relatively early in the course of these epileptic syndromes, especially in patients with LKS, epilepsy of unknown cause or/and structural and metabolic etiology.

\section{Reference}

1. Berg AT, Berkovic SF, Brodie MJ, Buchhalter J, Cross JH, et al. (2010) Revised terminology and concepts for organization of seizures and epilepsies: report of the ILAE Commission on Classification and Terminology, 2005-2009. Epilepsia 51(4): 676-685.

2. (2011-2013) ILAE Revised Terminology for Organization of Seizures and Epilepsies 2011-2013.

3. Patry G, Lyagoubi S, Tassinari CA (1971) Subclinical electrical status epilepticus induced by sleep in children: a clinical and electroencephalographic study of six cases. Archives of Neurology 24(3): 242-252.

4. Totila CE (1989) Proposal for revised classification of epilepsies and epileptic syndromes. Commission on Classification and Terminology of the International League against Epilepsy. Epilepsia 30(4): 389-399.

5. ILAE Organization of epilepsies. Comments, USA.

6. Schmitt B (2015) Sleep and epilepsy syndromes. Neuropediatrics 46(3): 171-180.

7. Tassinari CA, Cantalupo G, Rios-Pohl L, Giustina ED, Rubboli G (2009) 
Encephalopathy with status epilepticus during slow sleep: "the Penelope syndrome". Epilepsia 50(Suppl 7): 4-8.

8. Fernández IS, Chapman KE, Peters JM, Kothare SV, Nordli DR, et al. (2013) The tower of Babel: survey on concepts and terminology in electrical status epilepticus in sleep and continuous spikes and waves during sleep in North America. Epilepsia 54(4): 741-750.

9. Eksioglu YZ, Tas E, Takeoka M, Sarco D, Rotenberg A, et al. (2009) Clinical presentation and acute treatment of electrical status epilepticus in sleep and sleep potentiated spikes. Medical Publishing Practice, Philadelphia PA, USA, pp. A434-A434.

10. Bureau M (1995) Outstanding cases of CSWS and LKS: analysis of the data sheets provided by the participants, Continuous spikes and waves during slow sleep, John Libbey Publishing Ltd, UK, pp. 213-216.

11. Loddenkemper T, Fernández IS, Peters JM (2011) Continuous spike and waves during sleep and electrical status epilepticus in sleep. J Clin Neurophysio 28(2): 154-164.

12. Morikawa T, Seino M, Watanabe M (1995) Long-term outcome of CSWS syndrome. Continuous spikes and waves during slow sleep, John Libbey \& Company Ltd, London, UK, p. 27-36.

13. Tassinari CA, Rubboli G (2006) Cognition and paroxysmal EEG activities: from a single spike to electrical status epilepticus during sleep. Epilepsia 47(Suppl 2): 40-43.

14. Tas E, Takeoka M, Molino J, Gregas M, Eksioglu Y, et al. (2009) Thalamic lesions increase the frequency of spiking during sleep. Wiley-Blackwell Publishing, Malden, USA, pp. 479-479.

15. Van Hirtum-Das M, Licht EA, Koh S, Wu JY, Shields WD, et al. (2006) Children with ESES: variability in the syndrome. Epilepsy Res 70(Suppl 1): 248-258.

16. Guzzetta F, Battaglia D, Veredice C, Donvito V, Pane M, et al. (2005) Early thalamic injury associated with epilepsy and continuous spikewave during slow sleep. Epilepsia 46(6): 889-900.

17. Guerrini R, Genton P, Bureau M, Parmeggiani A, Salas-Puig X, et al (1998) Multilobar polymicrogyria, intractable drop attack seizures, and sleep-related electrical status epilepticus. Neurology 51(2): 504512.

18. Agarwal R, Kumar A, Tiwari VN, Chugani H (2016) Thalamic abnormalities in children with continuous spike-wave during slow-wave sleep: An F-18-fluorodeoxyglucose positron emission tomography perspective. Epilepsia 57(2): 263-271.

19. Kobayashi K, Hata H, Oka M, Ito M, Yoshinaga H, et al. (2006) Agerelated electrical status epilepticus during sleep and epileptic negative myoclonus in DRPLA. Neurology 66(5): 772-773.

20. Coutelier M, Andries S, Ghariani S, Dan B, Duyckaerts C, et al. (2008) Neuroserpin mutation causes electrical status epilepticus of slow-wave sleep. Neurology 71(1): 64-66.

21. Scheltens-de Boer M (2009) Guidelines for EEG in encephalopathy related to ESES/CSWS in children. Epilepsia 50(Suppl 7): 13-17.

22. Tassinari C, Rubboli G, Volpi L, Meletti S, d'Orsi G, et al. (2000) Encephalopathy with electrical status epilepticus during slow sleep or ESES syndrome including the acquired aphasia. Clinical Neurophysiology 111(Suppl 2): S94-S102.

23. Saltik S, Uluduz D, Cokar O, Demirbilek V, Dervent A (2005) A clinical and EEG study on idiopathic partial epilepsies with evolution into ESES spectrum disorders. Epilepsia 46(4): 524-533.

24. Aeby A, Poznanski N, Verheulpen D, Wetzburger C, Van Bogaert P (2005) Levetiracetam efficacy in epileptic syndromes with continuous spikes and waves during slow sleep: experience in 12 cases. Epilepsia 46(12): 1937-1942.
25. Gencpinar P, Dundar NO, Tekgul H (2016) Electrical status epilepticus in sleep (ESES)/continuous spikes and waves during slow sleep (CSWS) syndrome in children: An electroclinical evaluation according to the EEG patterns. Epilepsy \& Behavior 61: 107-111.

26. Heinzle BKB, Bast T, Critelli H, Huber R, Schmitt B (2016) AgeDependency of Location of Epileptic Foci in "Continuous Spike-andWaves during Sleep": A Parallel to the Posterior-Anterior Trajectory of Slow Wave Activity. Neuropediatrics 48(1): 36-41.

27. Japaridze N, Muthuraman M, Dierck C, Spiczak S, Boor R, et al. (2016) Neuronal networks in epileptic encephalopathies with CSWS. Epilepsia 57(8): 1245-1255.

28. Singhal NS, Sullivan JE (2014) Continuous spike-wave during slow wave sleep and related conditions. ISRN neurology 2014: 619079.

29. Veggiotti P, Pera MC, Teutonico F, Brazzo D, Balottin U, et al. (2012) Therapy of encephalopathy with status epilepticus during sleep (ESES/ CSWS syndrome): an update. Epileptic Disorders 14(1): 1-11.

30. Sánchez Fernández I, Chapman K, Peters JM, Klehm J, et al. (2014) Treatment for continuous spikes and waves during sleep (CSWS): survey on treatment choices in North America. Epilepsia 55(7): 10991108.

31. Kramer U, Sagi L, Goldberg-Stern H, Zelnik N, Nissenkorn A, et al. (2009) Clinical spectrum and medical treatment of children with electrical status epilepticus in sleep (ESES). Epilepsia 50(6): 1517-1524.

32. Atkins M, Nikanorova M (2011) A prospective study of levetiracetam efficacy in epileptic syndromes with continuous spikes-waves during slow sleep. Seizure 20(8): 635-639.

33. Caraballo RH, Veggiotti P, Kaltenmeier MC, Piazza E, Gamboni B, et al. (2013) Encephalopathy with status epilepticus during sleep or continuous spikes and waves during slow sleep syndrome: a multicenter, long-term follow-up study of 117 patients. Epilepsy res 105(1-2): 164-173.

34. Grosso S, Parisi P, Giordano L, di Bartolo R, Balestri P (2014) Lacosamide efficacy in epileptic syndromes with continuous spike and waves during slow sleep (CSWS). Epilepsy res 108(9): 1604-1608.

35. Vrielynck P, Marique P, Ghariani S, Lienard F, de Borchgrave V, et al. (2016) Topiramate in childhood epileptic encephalopathy with continuous spike-waves during sleep: A retrospective study of 21 cases. Eur J Paediatr Neurol 21(2): 305-311.

36. Fine AL, Wirrell EC, Wong-Kisiel LC, Nickels KC (2015) Acetazolamide for electrical status epilepticus in slow-wave sleep. Epilepsia 56(9): e134-e138.

37. Buzatu M, Bulteau C, Altuzarra C, Dulac 0, Van Bogaert P (2009) Corticosteroids as treatment of epileptic syndromes with continuous spike-waves during slow-wave sleep. Epilepsia 50(Suppl 7): 68-72.

38. Okuyaz Ç, Aydın K, Gücüyener K, Serdaroğlu A (2005) Treatment of electrical status epilepticus during slow-wave sleep with high-dose corticosteroid. Pediatr Neurol 32(1): 64-67.

39. Chen J, Yang Z, Liu X, Ji T, Fu N, et al. (2014) [Efficacy of methylprednisolone therapy for electrical status epilepticus during sleep in children]. Zhonghua Er Ke Za Zhi 52(9): 678-682.

40. Chen J, Cai F, Jiang L, Hu Y, Feng C (2016) A prospective study of dexamethasone therapy in refractory epileptic encephalopathy with continuous spike-and-wave during sleep. Epilepsy Behav 55: 1-5.

41. Billard C, Autret A, Laffont F, Lucas B, Degiovanni E (1982) Electrical status epilepticus during sleep in children: a reappraisal from eight new cases. In: Sterman MB, Shouse P, Passouant P (Eds.), Sleep and epilepsy. Academic Press, San Diego, USA, pp. 481-494.

42. Kellermann K (1978) Recurrent aphasia with subclinical bioelectric status epilepticus during sleep. Eur J Pediatr 128(3): 207-212. 
43. Inutsuka M, Kobayashi K, Oka M, Hattori J, Ohtsuka Y (2006) Treatment of epilepsy with electrical status epilepticus during slow sleep and its related disorders. Brain Dev 28(5): 281-286.

44. Nikanorova M, Miranda MJ, Atkins M, Sahlholdt L (2009) Ketogenic diet in the treatment of refractory continuous spikes and waves during slow sleep. Epilepsia 50(5): 1127-1131.

45. Caraballo R, Fontana E, Michelizza B, Zullini E, Sgro V, et al. (1989) Carbamazepina,"assenzeatipiche", crisi "atoniche" e stato di PO continua del sonno (POCS). Boll Lega It Epil 66: 379-381.

46. Lerman P (1986) Seizures induced or aggravated by anticonvulsants. Epilepsia 27(6): 706-710.

47. Loddenkemper T, Cosmo G, Kotagal P, Haut J, Klaas P, et al. (2009) Epilepsy surgery in children with electrical status epilepticus in sleep. Neurosurgery 64(2): 328-337.

48. Battaglia D, Veggiotti P, Lettori D, Tamburrini G, Tartaglione T, et al. (2009) Functional hemispherectomy in children with epilepsy and CSWS due to unilateral early brain injury including thalamus: sudden recovery of CSWS. Epilepsy research 87(2-3): 290-298.

49. Jeong A, Strahle J, Vellimana AK, Limbrick DD, Smyth MD, et al. (2017) Hemispherotomy in children with electrical status epilepticus of sleep. J Neurosurg Pediatr 19(1): 56-62.

50. Parker APJ, Polkey CE, Binnie CD, Madigan C, Ferrie CD, et al. (1999)
Vagal Nerve Stimulation in Epileptic Encephalopathies. Pediatrics 103(4): 778-782.

51. Aicardi J (1999) Vagal nerve stimulation in epileptic encephalopathies. Pediatrics 103(4 Pt 1): 821-822.

52. Carosella CM, Greiner HM, Byars AW, Arthur TM, Leach JL, et al. (2016) Vagus Nerve Stimulation for Electrographic Status Epilepticus in SlowWave Sleep. Pediatric neurology 60: 66-70.

53. Faria P, Fregni F, Sebastião F, Dias AI, Leal A (2012) Feasibility of focal transcranial DC polarization with simultaneous EEG recording: Preliminary assessment in healthy subjects and human epilepsy. Epilepsy Behav 25(3): 417-425.

54. Pera MC, Brazzo D, Altieri N, Balottin U, Veggiotti P (2013) Long-term evolution of neuropsychological competences in encephalopathy with status epilepticus during sleep: A variable prognosis. Epilepsia 54(Suppl 7): 77-85.

55. Seegmüller C, Deonna T, Mayor Dubois C, Valenti-Hirsch MP, Hirsch E, et al. (2012) Long-term outcome after cognitive and behavioral regression in nonlesional epilepsy with continuous spike-waves during slow-wave sleep. Epilepsia 53(6): 1067-1076.

56. Rousselle C, Revol M (1995) Relations between cognitive functions and continuous spikes and waves during slow sleep. Continuous spikes and waves during slow sleep, John Libbey, UK, pp.123-133.

Your next submission with Juniper Publishers
will reach you the below assets
- Quality Editorial service
- Swift Peer Review
- Reprints availability
- E-prints Service
- Manuscript Podcast for convenient understanding
- Global attainment for your research
- Manuscript accessibility in different formats
( Pdf, E-pub, Full Text, Audio)
- Unceasing customer service
Track the below URL for one-step submission
https://juniperpublishers.com/online-submission.php

